\title{
Resolving static offsets from high-rate GPS data: the 2003 Tokachi-oki earthquake
}

\author{
Kristine M. Larson ${ }^{1}$ and Shin'ichi Miyazaki ${ }^{2}$ \\ ${ }^{1}$ Department of Aerospace Engineering Sciences, University of Colorado, Boulder, USA \\ ${ }^{2}$ Department of Geophysics, Kyoto University, Kyoto, Japan \\ (Received May 6, 2008; Accepted June 6, 2008; Online published September 8, 2008)
}

\begin{abstract}
The $M_{\mathrm{w}} 8.02003$ Tokachi-oki earthquake offshore Hokkaido is the largest earthquake observed to date by a dense GPS network (GEONET). These GPS data are important both for resolving the geodetic signature of the earthquake itself and studies of postseismic deformation. Because GPS positions are generally estimated by averaging 24 hours of observations, it can be difficult to separate the effects of the earthquake and early postseismic deformation. In order to address this difficulty, a Kalman filtering methodology is developed that allows the estimation of the static offsets for the mainshock, its largest aftershock, and postseismic deformation in the first 24 hours. The static offsets computed for this study can be used for earthquake rupture studies while the early postseismic data can be used to evaluate frictional properties of the fault.
\end{abstract}

Key words: GPS, great earthquake, geodetic data, static offset, postseismic deformation.

\section{Introduction}

Continuously operating GPS networks are now routinely used to estimate the "static" offsets associated with large earthquakes. Typically the position of each receiver is estimated by averaging data from the previous 24 hours and then comparing it to a position estimated by averaging the next 24 hours of data. This methodology is adequate if there is no significant postseismic deformation in these first 24 hours. Depending on the location of near-fault GPS sites, measurements made in the vicinity of great earthquakes, on the other hand, will most certainly require a different data analysis strategy. Even the very small 2004 Parkfield earthquake ( $M$ 6) showed significant postseismic deformation in the first 24 hours (Langbein et al., 2005). Great earthquakes are also sometimes preceeded or followed by very large earthquakes, called foreshocks and aftershocks. These further complicate the estimation of static offsets for the mainshock. In this paper a geodetic processing method is described that can accurately resolve both static offsets and immediate postseismic deformation. By estimating them simultaneously, the estimated values are more likely to be consistent. The static offsets can be used in fault rupture models by constraining cumulative slip, whereas the transient position changes are of great interest for studying the mechanical behavior of faults.

\section{Tokachi-oki Earthquake}

The focus of this paper is the $M_{\mathrm{s}} 8.0$ Tokachi-oki earthquake (Yamanaka and Kikuchi, 2003). The mainshock occurred on 2003 September 25 at 19:50 UTC. The epicentral location was $\sim 80 \mathrm{~km}$ offshore Hokkaido, the northern

Copyright (c) The Society of Geomagnetism and Earth, Planetary and Space Sciences (SGEPSS); The Seismological Society of Japan; The Volcanological Society of Japan; The Geodetic Society of Japan; The Japanese Society for Planetary Sciences; TERRAPUB island of Japan (Fig. 1). The rupture was close to the location of the 1952 Tokachi-oki earthquake (Yamanaka and Kikuchi, 2003). Horizontal deformation in Hokkaido exceeded 1 meter (Miura et al., 2004), with vertical deformation of $20 \mathrm{~cm}$ observed along the southern coast nearest the epicenter. Seventy-eight minutes after the mainshock, a $M_{\mathrm{S}} 7.4$ aftershock occurred. The location of its epicenter is also shown in Fig. 1.

The GPS network (GEONET) dedicated to geodesy and geophysics in Japan is operated by the Geographical Survey Institute (GSI). It consists of more than 1000 receivers/stations (Miyazaki et al., 1997). GEONET records and distributes GPS measurements at a 30-second sampling rate. At the time of the Tokachi-oki earthquake the GEONET sites were operated with Trimble 5700 GPS receivers and choke-ring antennas. Each receiver has a backup power system, thus ensuring that the instrument will operate if a large earthquake removes local power sources. Very few 30-second GPS data were lost during the Tokachioki earthquake sequence, providing the best GPS recording of a great earthquake ever made. A total of 55 sites from Hokkaido and the northern portion of Honshu will be used in this study (Fig. 1). Additional sites used in the analysis are located on the Japanese island of Honshu (USUD), Russia (YAKT) and China (WUHN); their data are coordinated by the International GNSS Service (IGS). Information about these sites can be found at http://igscb.jpl.nasa.gov.

Static offsets for the Tokachi-oki earthquake have previously been estimated by GSI (2003) and were used by Koketsu et al. (2004) in their joint seismic-geodetic slip inversion and by Miura et al. (2004). Because of the large aftershock, the post-earthquake position was based on data between 20:00 and 21:00 UTC on September 25. To study postseismic deformation following this earthquake sequence, static offsets for this aftershock must also be es- 


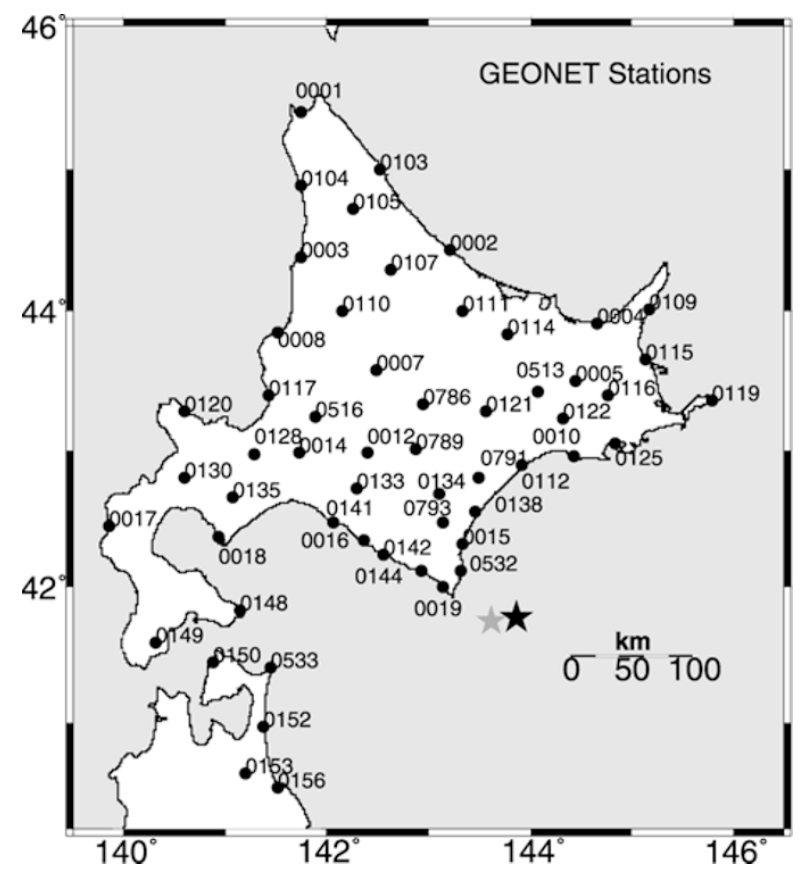

Fig. 1. GEONET stations used in this study. Latitude and longitudes of the sites are given in Table 2. The main shock (large star) and the largest aftershock (small gray star) epicenters of the 2003 Tokachi-oki earthquake are also shown.

timated.

\section{GPS Analysis}

\subsection{Parameter estimation}

Except for its treatment of position changes, the GPS data used in this study were analyzed using fairly standard techniques and the GIPSY software (Lichten and Borders, 1987). Precise IGS orbits (http://igscb.jpl.nasa.gov) defined in the ITRF2000 reference frame (Altamimi et al., 2002) were held fixed along with ITRF2000 station coordinates for YAKT. The positions of two other sites, USUD and WUHN, were also not allowed to vary with time. USUD was used as the reference clock.

Although daily positions are generally estimated along with azimuthal gradient terms for the troposphere (Miyazaki et al., 2003), because we are estimating stochastic positions, only a single time-varying zenith delay was estimated for each site. This strategy may not be appropriate for a region that experiences significant azimuthal variations in water vapor distribution. The Niell (1996) mapping function is used to relate zenith delays to the measurements. Other estimated parameters are satellite and receiver clocks and carrier phase ambiguities. Improved phase center variations of Hatanaka et al. (2001) were used to correct the GEONET data. P1-C1 biases from CODE were used to allow mixing of Trimble (GEONET) and Ashtech receivers (YAKT, USUD, and WUHN). Over 95\% of carrier phase ambiguities were resolved (Blewitt, 1989). Ocean tide loading corrections were obtained from the Onsala Ocean Loading Provider (http://www.oso.chalmers.se/ loading/) using GOT00.2 (Goddard Ocean Tide Model). Because of computational limits in GIPSY, the data were analyzed in 10 subnetworks consisting of 8 stations: 5 GEONET sites along with YAKT, USUD, and WUHN. Data from 2003 September 25 00:00 through 2003 September 27 08:00 UTC were used; positions were output every 4 minutes.

\subsection{Kalman filtering}

As with all GPS data, independent 30 -sec position estimates are contaminated by the effects of satellite geometry and multipath. In order to suppress these errors, we have taken advantage of the Kalman filter embedded in the GIPSY software (Lichten and Borders, 1987). The software allows white noise, colored noise, and random walk estimation of position. Of these three, random walk estimation has been shown to work well to suppress noise in volcanic monitoring environments (Larson et al., 2001) where deformation is slowly varying. This processing technique would not work well where there are large ground displacements such as those caused by an earthquake. For earthquakes, a white noise position estimation technique is preferred because no assumptions are made about the nature of the deformation. For this reason, white noise position estimation has been used extensively to measure seismic waves, e.g. Larson et al. (2003) and Miyazaki et al. (2004b). Unfortunately, the trade-off one makes by using white noise estimation is that very large geometric/multipath signals are still present in the time series.

Figure 2 illustrates the challenges associated with using a white noise position estimation stategy. Station 0003 is approximately $330 \mathrm{~km}$ from the epicenter, so only the mainshock is visible in the timeseries. From visual inspection of the time series before and after the mainshock, it is clear that the horizontal components are much better determined than the vertical component. Note also that the noise in the position estimates is not randomly distributed, with large systematic signatures in all three components. The systematic noise is particularly pronounced for the vertical component. The estimate of the static offsets-for the mainshock in this example-is thus heavily influenced by which averaging (e.g. 15 minutes, 5 minutes) interval one uses. For this particular earthquake, at least for the sites near the epicenter, one is restricted to using no more than one hour be-

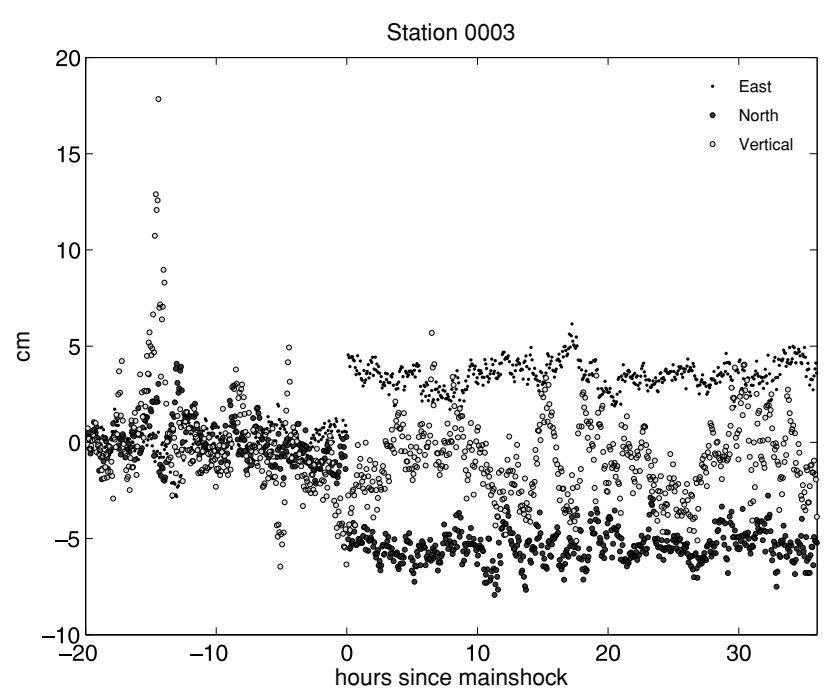

Fig. 2. GPS time series at station 0003 using whitenoise positioning strategy. 
Table 1. Resolution statistics.

\begin{tabular}{lccccccc}
\hline Test & \multicolumn{3}{c}{ Mean $(\mathrm{cm})$} & & \multicolumn{3}{c}{ Standard deviation $(\mathrm{cm})$} \\
\cline { 2 - 3 } \cline { 6 - 8 } & East & North & Vertical & & East & North & Vertical \\
\hline 1. Choi $(2007)$ & -0.07 & -0.51 & -1.17 & & 0.30 & 0.38 & 1.26 \\
2. Add WUHN & -0.11 & 0.04 & -1.12 & & 0.30 & 0.39 & 1.30 \\
3. Loose $\sigma_{\text {rw }}$ & -0.22 & 0.26 & -1.01 & & 0.37 & 0.50 & 1.16 \\
4. Tighter tropo & -0.01 & 0.01 & -0.92 & & 0.31 & 0.39 & 0.93 \\
\hline
\end{tabular}

cause of the large aftershock which caused significant displacements in this region.

Much of the geometric/multipath noise seen in Fig. 2 can be removed if 1-Hz GPS data are available for multiple days (Johnson et al., 2006; Larson et al., 2007). The extra days of data are needed to create an empirical noise correction profile. Since most GPS monitoring systems operate at 30sec, this approach is only available for a limited number of datasets. For the Tokachi-oki dataset, most of the $1-\mathrm{Hz}$ data near the epicenter were lost when the telemetry systems lost power. The 30 -second sampled data, however, are complete. Thus an analysis technique developed for the 30sec dataset, that combines white noise position estimation at the times of the earthquakes with random walk parameterization (Larson et al., 2001) at other times would yield both precise static offsets and postseismic deformation.

\subsection{Filtering strategy}

GIPSY was modified for this paper so that the position estimates are modeled as tightly constrained random walks before and after the earthquake, but modeled as a white noise process (a priori standard deviation of 100 meters) at the time of the earthquakes. Before addressing the signals from the mainshock and aftershock, this technique was first used to evaluate whether a null signal could be resolved. The twenty hours of data before the mainshock were used for this purpose. A whitenoise offset was estimated at the mid-point of the data (10:00 UTC). The "static offset" of the earthquake was then calculated for each component for each of the 55 GEONET sites (no static offsets were estimated for USUD, YAKT, or WUHN). The mean and standard deviation of the static offsets are reported in Table 1.

The noise in the position estimates will be controlled by the process noise standard deviation, or $\sigma_{\text {rw }}$. This parameter is given in units of the square root of the position variance per time. Larson et al. (2001) suggested values of $1-7.5 \times 10^{-8} \mathrm{~km} / \sqrt{\mathrm{sec}}$ (equivalent to $0.06-0.45 \mathrm{~cm} / \sqrt{\mathrm{hr}}$ ) should be used, depending on how rapidly deformation is taking place (units for $\sigma_{\text {rw }}$ will hereafter be assumed to be $\mathrm{km} / \sqrt{\mathrm{sec}}$ ). A volcanic inflation event documented in that paper, with $4 \mathrm{~cm}$ of displacement in several hours, was suppressed by a small $\sigma_{\text {rw }}$ value of $1 \times 10^{-8}$. For the slower postseismic displacements expected for the Tokachioki event ( $4 \mathrm{~cm}$ in 24 hours for the site closest to the epicenter), a value $1 \times 10^{-8}$ is not likely to suppress the signal. Initial simulations tested for various $\sigma_{\text {rw }}$ values reached the same conclusion (Choi, 2007). The null statistics for a $\sigma_{\text {rw }}$ value of $1 \times 10^{-8}$ are reported as test 1 in Table 1 . Unfortunately, the statistics reported for this null signal test also showed there to be a bias in the north component of $5 \mathrm{~mm}$. Since Choi (2007) had only used USUD and YAKT as fixed sites, we hypothesized that orientational control of the net-

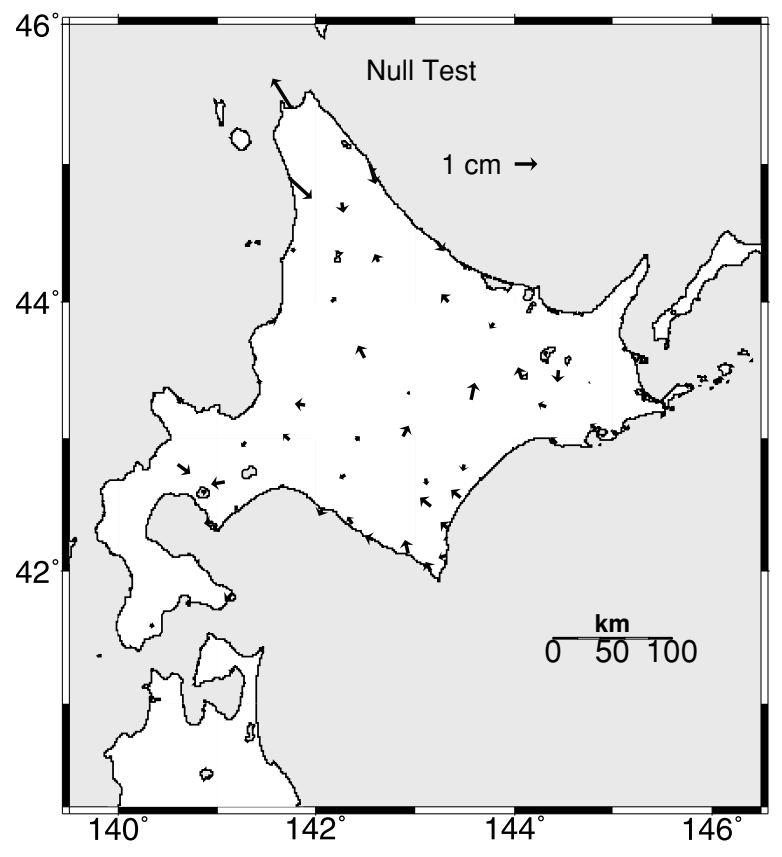

Fig. 3. Horizontal results for test 4 (Table 1) for null signal analysis.

work was not sufficient. When a third fixed site was added, WUHN (test 2), the north component bias was reduced to a negligible level, $0.4 \mathrm{~mm}$. In test 3 a looser $\sigma_{\text {rw }}$ of $2.5 \times 10^{-8}$ was used; this constraint significantly degraded how well the null signal could be resolved. The final test was made in an effort to improve the vertical precision. Choi (2007) used a very loosely constrained zenith troposphere term, $\sigma_{\text {rw }}$ of $1 \times 10^{-7}$. Reducing this value to $5 \times 10^{-8}$ (test 4 ) produced significantly better vertical precision and a smaller bias (reduced from 11 to $9 \mathrm{~mm}$ ) than for previous tests. Final solutions for the Tokachi-oki data analysis will use the extra reference site (WUHN), position random walk constraint of $1 \times 10^{-8}$ and troposphere constraint of $5 \times 10^{-8}$. The horizontal results for test 4 are shown in Fig. 3. Based on the 55 stations used in this study, the standard deviations for the east, north, and vertical static offsets are expected to be on the order of 3,4 , and $9 \mathrm{~mm}$.

\section{Results}

To avoid corrupting the static offsets with dynamic displacements for the mainshock, 5 minutes of data after the epoch time were removed. The static offset is subsequently removed from each component timeseries by subtracting the offset estimated for the epoch time. An identical procedure was used to remove the static offset for the $M 7.4$ aftershock, although a smaller time-window of data was removed ( 2 minutes). Although one would not expect a mea- 


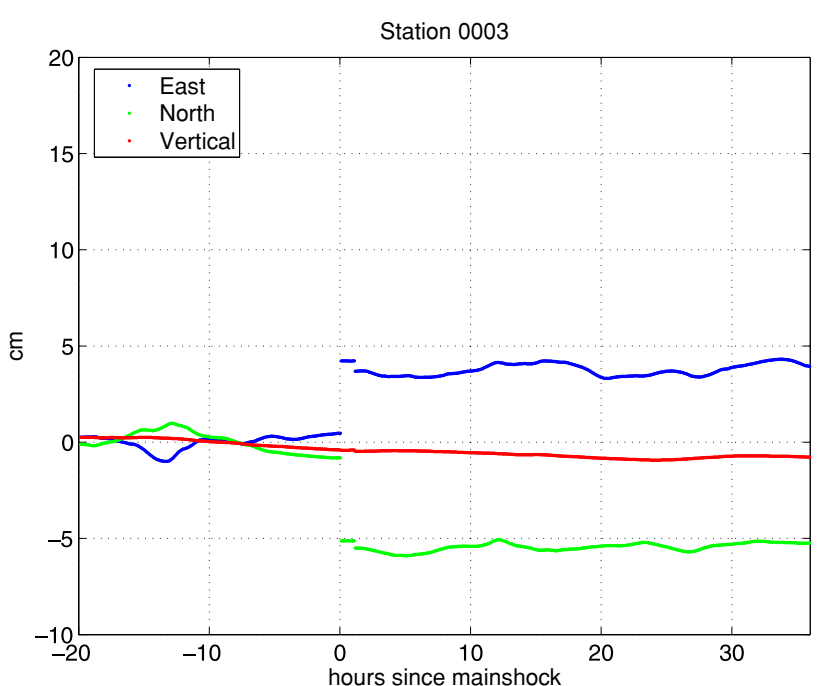

Fig. 4. GPS time series at station 0003 using combined whitenoiserandom walk analysis stategy.

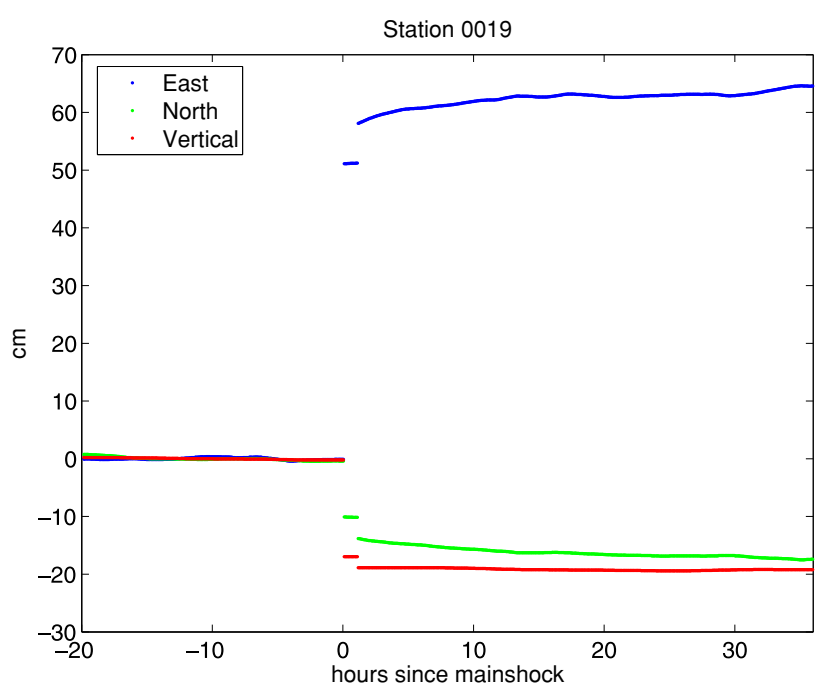

Fig. 5. GPS time series at station 0019 using combined whitenoise-randomwalk analysis strategy.
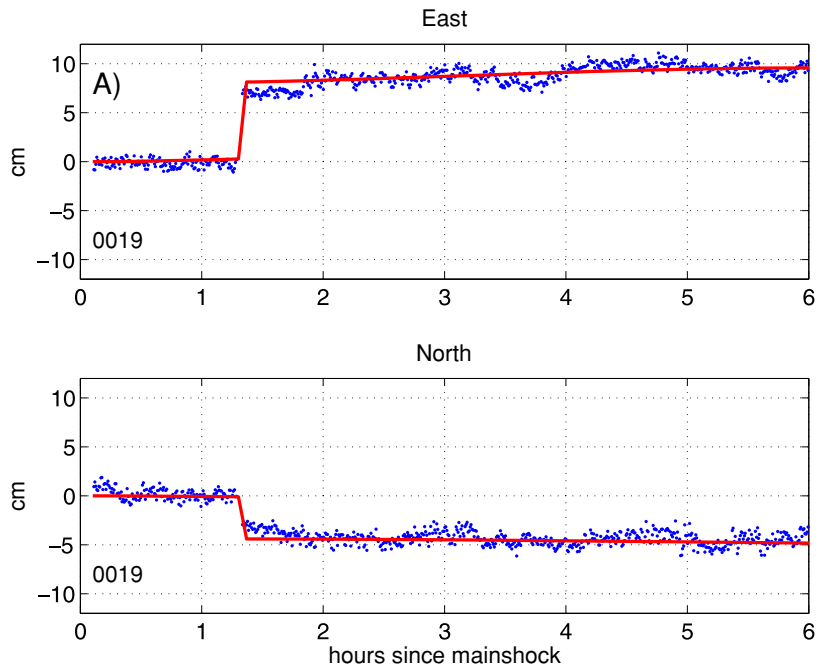

Fig. 6. Horizontal time-series for GPS stations 0019, 0142, 0144, and 0532 are given in subfigures A-D. The Kalman filtered solutions are in red; the white-noise position estimates are in blue.
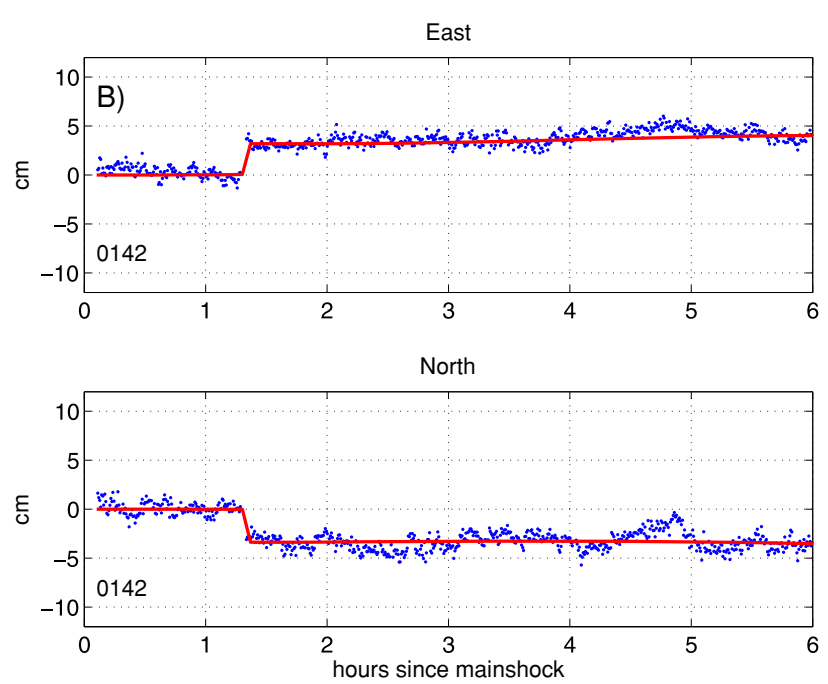

East
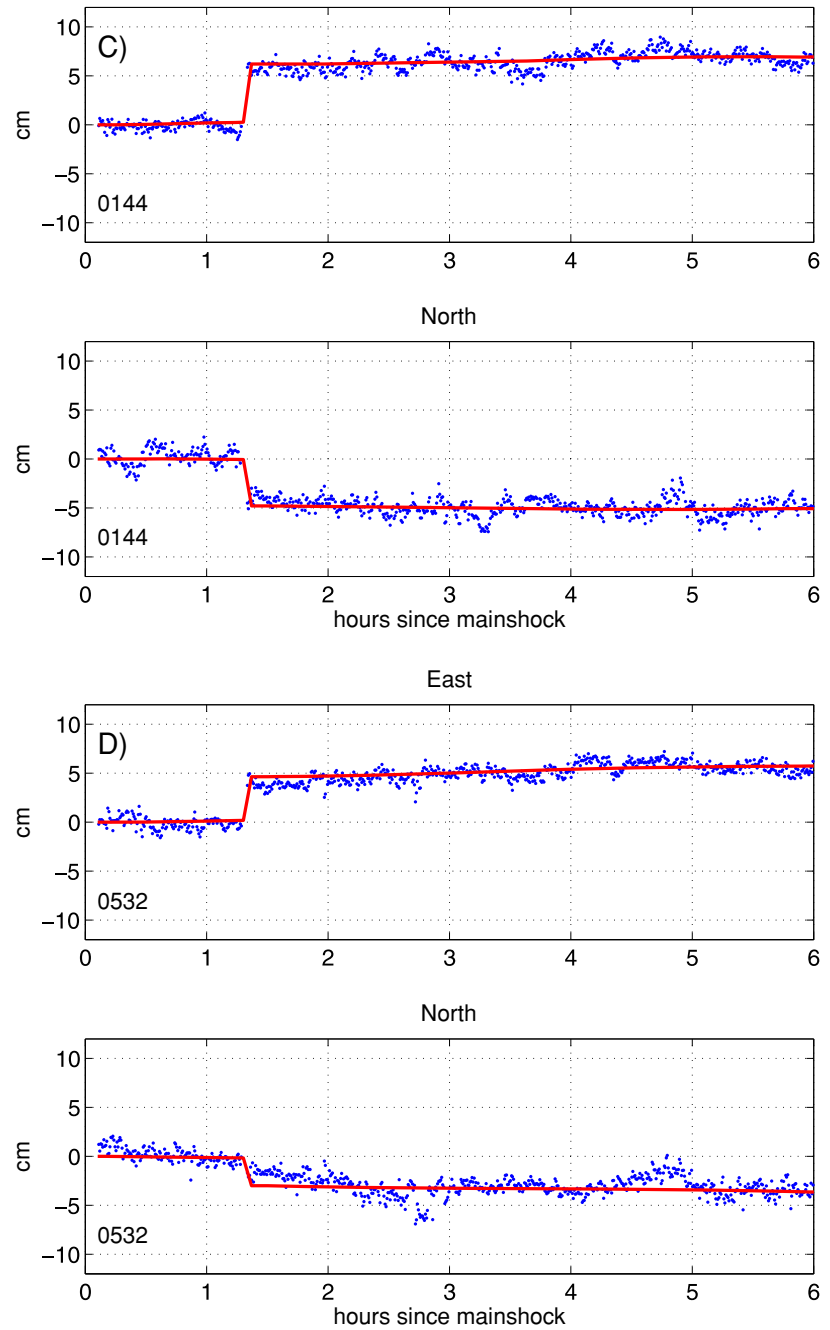

Fig. 6. (continued).

surable static offset at far sites for the aftershock, it was estimated for all stations to ensure that all sites were treated consistently.

Typical results for the network are shown first as time series. In Fig. 4, a time series for station 0003 is shown again, using the same $y$-axis limits as Fig. 2. The displacements for the site are now much smoother than the whitenoise es- 


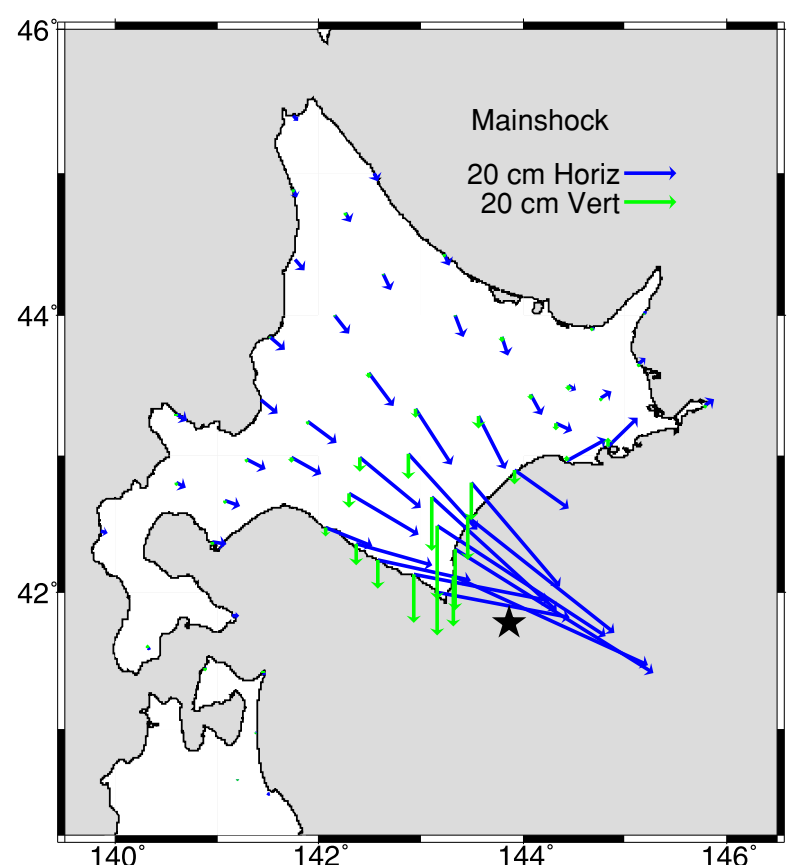

Fig. 7. Static offsets for the Tokachi-Oki mainshock. One standard deviation uncertainties are 3,4 , and $9 \mathrm{~mm}$ for the east, north, and vertical components, respectively.

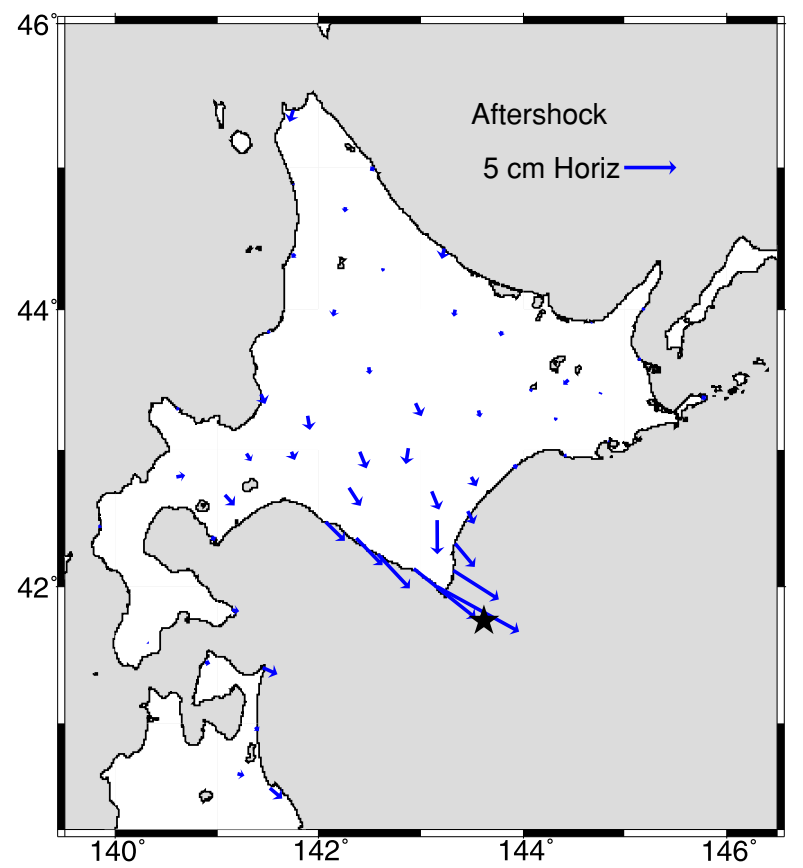

Fig. 8. Static offsets for the $M 7.4$ aftershock. The scale for displacement is 5 times larger than that used in Fig. 7. One standard deviation uncertainties are 3, 4, and $9 \mathrm{~mm}$ for the east, north, and vertical components, respectively.

timates shown in Fig. 2. We emphasize that smoothness of the position estimates should not be interpreted that the solutions are free of error. Position changes for this site are clearly seen in the 20 hours before the earthquake that are unlikely to be true ground deformation. No significant deformation is seen at the time of the $M 7.4$ aftershock $(<5 \mathrm{~mm})$, and no significant postseismic deformation is observed either. This is not surprising given the distance of

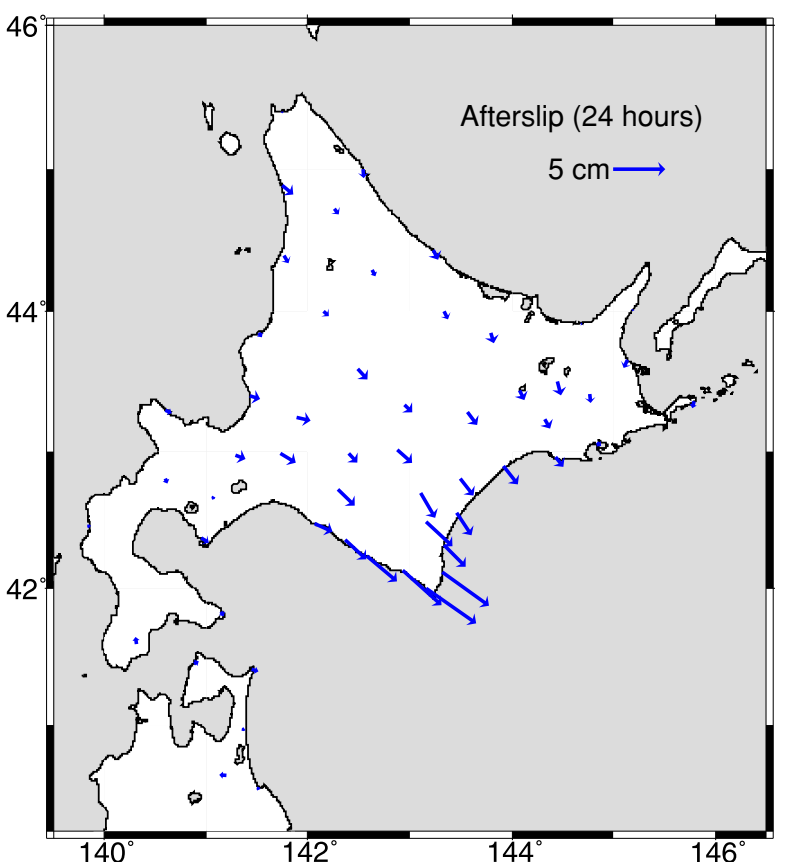

Fig. 9. Cumulative horizontal displacement 24 hours after the mainshock. No significant vertical afterslip is observed.

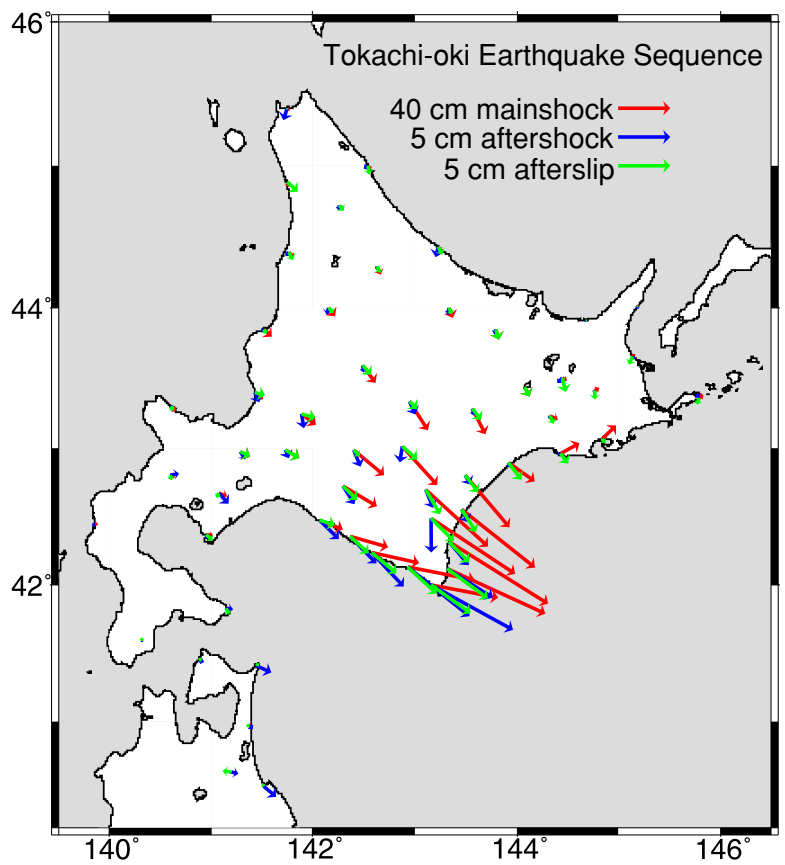

Fig. 10. Summary of horizontal displacements for the mainshock, aftershock, and first 24 hours of afterslip. Note scale difference for mainshock displacements.

station 0003 from the epicenters $(>330 \mathrm{~km})$.

As shown in Fig. 5, Site 0019 shows the largest postseismic displacements, with over $50 \mathrm{~mm}$ of horizontal displacements in the first 24 hours, with the most pronounced motion shown in the early hours after the $M 7.4$ aftershock. No significant postseismic displacements are observed in the vertical component. This is consistent with previous analyses of postseismic deformation that used 24-hour position averages (Miyazaki et al., 2004a; Ozawa et al., 2004). 
Table 2. Static offsets-Part I (cm).

\begin{tabular}{|c|c|c|c|c|c|c|c|c|}
\hline \multirow{3}{*}{$\begin{array}{c}\text { Station } \\
0001\end{array}$} & \multirow{2}{*}{\multicolumn{2}{|c|}{$\begin{array}{c}\text { Longitude } \quad \text { Latitude } \\
\text { degrees }\end{array}$}} & \multicolumn{3}{|c|}{ Mainshock } & \multicolumn{3}{|c|}{ Aftershock } \\
\hline & & & \multirow{2}{*}{$\begin{array}{r}\text { East } \\
1.6\end{array}$} & \multirow{2}{*}{$\begin{array}{r}\text { North } \\
-1.9\end{array}$} & \multirow{2}{*}{$\begin{array}{c}\text { Vertical } \\
0.2\end{array}$} & \multirow{2}{*}{$\begin{array}{l}\text { East } \\
-0.4\end{array}$} & \multirow{2}{*}{$\begin{array}{c}\text { North } \\
-1.2\end{array}$} & \multirow{2}{*}{$\begin{array}{c}\text { Vertical } \\
-0.2\end{array}$} \\
\hline & 141.75 & 45.40 & & & & & & \\
\hline 0002 & 143.22 & 44.43 & 1.8 & -4.5 & -0.6 & -0.2 & -0.9 & -0.3 \\
\hline 0003 & 141.76 & 44.40 & 3.6 & -4.3 & -0.2 & -0.3 & -0.4 & 0.2 \\
\hline 0004 & 144.68 & 43.92 & 1.0 & -1.1 & -1.3 & -0.1 & -0.2 & 0.4 \\
\hline 0005 & 144.45 & 43.51 & 2.9 & -1.9 & -1.7 & -0.5 & -0.4 & -0.3 \\
\hline 0007 & 142.48 & 43.59 & 9.6 & -13.1 & -2.5 & 0.1 & -0.7 & 0.4 \\
\hline 0008 & 141.51 & 43.85 & 5.8 & -5.1 & -0.9 & -0.3 & -0.2 & 0.0 \\
\hline 0010 & 144.43 & 42.96 & 15.1 & 8.4 & 2.0 & -0.3 & -0.0 & -0.1 \\
\hline 0012 & 142.40 & 42.98 & 23.5 & -19.6 & -5.0 & 0.7 & -1.6 & -0.9 \\
\hline 0014 & 141.73 & 42.98 & 11.4 & -6.5 & -1.4 & 0.4 & -0.9 & -0.1 \\
\hline 0015 & 143.33 & 42.32 & 76.3 & -47.7 & -24.1 & 1.9 & -2.3 & -0.7 \\
\hline 0016 & 142.36 & 42.36 & 29.1 & -8.2 & -8.4 & 2.5 & -2.6 & -0.5 \\
\hline 0017 & 139.86 & 42.45 & 2.7 & -0.8 & -1.1 & -0.2 & -0.2 & -0.2 \\
\hline 0018 & 140.94 & 42.37 & 5.5 & -0.9 & -1.8 & 0.2 & -0.5 & -0.7 \\
\hline 0019 & 143.16 & 42.01 & 51.3 & -9.8 & -16.7 & 7.9 & -4.3 & -1.9 \\
\hline 0103 & 142.54 & 45.00 & 1.5 & -3.5 & 0.1 & -0.4 & -0.3 & 0.1 \\
\hline 0104 & 141.74 & 44.89 & 1.3 & -3.2 & -0.8 & 0.1 & -0.2 & 0.3 \\
\hline 0105 & 142.27 & 44.73 & 2.0 & -3.9 & -0.7 & -0.1 & -0.5 & 0.1 \\
\hline 0107 & 142.63 & 44.29 & 2.9 & -6.4 & -0.2 & -0.1 & -0.3 & -0.2 \\
\hline 0109 & 145.19 & 44.02 & 1.0 & 0.9 & -0.4 & -0.2 & -0.4 & -0.3 \\
\hline 0110 & 142.15 & 44.01 & 5.3 & -7.0 & -0.5 & -0.2 & -0.8 & -0.0 \\
\hline 0111 & 143.33 & 44.01 & 3.0 & -8.2 & -0.7 & -0.1 & -0.7 & -1.1 \\
\hline 0112 & 143.93 & 42.89 & 20.6 & -14.7 & -5.5 & 0.1 & -0.4 & 0.1 \\
\hline 0114 & 143.79 & 43.85 & 2.4 & -7.6 & -2.3 & -0.1 & -0.4 & -0.0 \\
\hline 0115 & 145.13 & 43.66 & 2.5 & 2.1 & -0.9 & 0.2 & -0.2 & 0.2 \\
\hline 0116 & 144.77 & 43.41 & 3.8 & 2.4 & -0.7 & -0.0 & -0.1 & -0.4 \\
\hline 0117 & 141.43 & 43.40 & 6.4 & -5.3 & 0.4 & 0.4 & -0.9 & -1.1 \\
\hline 0119 & 145.80 & 43.37 & 3.6 & 2.5 & -1.1 & -0.3 & 0.4 & 0.6 \\
\hline 0120 & 140.60 & 43.29 & 4.3 & -2.7 & -0.2 & 0.3 & -0.0 & 0.1 \\
\hline 0121 & 143.56 & 43.29 & 10.2 & -20.2 & -4.3 & 0.1 & -0.6 & -0.2 \\
\hline 0122 & 144.32 & 43.23 & 6.3 & -3.0 & -2.0 & -0.1 & -0.4 & -0.1 \\
\hline 0125 & 144.84 & 43.06 & 11.2 & 11.0 & 3.9 & 0.2 & -0.1 & -0.2 \\
\hline 0128 & 141.29 & 42.97 & 7.3 & -3.9 & -0.6 & 0.5 & -0.8 & -0.1 \\
\hline
\end{tabular}

The smoothed time series in Fig. 5 also suggest that there was little deformation at site 0019 between the earthquakes. In Fig. 6, we show both the white noise position estimates and the smoothed time series for site 0019, along with sites closest to the epicenters: 0142,0144 , and 0532 . These time series show that noise characteristics vary by site; for example, site 0532 shows significantly greater noise than the other 3 sites. They also confirm that there were not large displacements at any of the sites in the time period between the earthquakes, confirming that the smoothness constraint is not suppressing estimation of ground motion.

A compilation of the mainshock static offsets determined for this dataset is shown in Fig. 7 and tabulated in Tables 23 . These results are in qualitiative agreement with previous geodetic studies of the earthquake (Koketsu et al., 2004; Miura et al., 2004). The largest displacements are along the southern tip of Hokkaido. To the northeast, the static offsets show much smaller but significant northeastward displacments. No significant static displacements are estimated for the sites on Honshu. The aftershock static offsets are reported in Fig. 8 and Tables 2-3. Only the sites in the southern most tip of Hokkaido record significant static offsets. Note the scale difference between Figs. 7 and 8; this has the effect of emphasizing the uncertainty in the static offsets which was difficult to see in Fig. 7. The static offsets for both the mainshock and aftershock can be used to provide cumulative slip constraints on rupture models (Wald and Graves, 2001). Updated cumulative slip models based on these estimates are available in Miyazaki and Larson (2008).

A snapshot of early postseismic deformation is shown in Fig. 9 (at the same scale as was used for the aftershock in Fig. 8). While insignificant at the vast majority of GPS sites (Honshu and far coastal sites on Hokkaido), southern coastal regions of Hokkaido experienced 20-55 mm of horizontal displacement. For example, sites 0019 and 0532 move almost as much in the first 24 hours as they did during the $M 7.4$ aftershock. The displacements from the mainshock, aftershock, and initial postseismic deformation are summarized in Fig. 10. Although the scale has been compressed for the mainshock, this figure makes it clear that the pattern of deformation for the three time periods is quite different. Postseismic displacements can be seen throughout the network, whereas displacements due to the aftershock are concentrated near the epicenter. Displacements due to the mainshock are rotated eastwards relative to 
Table 3. Static offsets-Part II (cm).

\begin{tabular}{|c|c|c|c|c|c|c|c|c|}
\hline \multirow{3}{*}{$\begin{array}{c}\text { Station } \\
0130\end{array}$} & \multirow{2}{*}{\multicolumn{2}{|c|}{$\begin{array}{c}\text { Longitude } \quad \text { Latitude } \\
\text { degrees }\end{array}$}} & \multicolumn{3}{|c|}{ Mainshock } & \multicolumn{3}{|c|}{ Aftershock } \\
\hline & & & \multirow{2}{*}{$\begin{array}{r}\text { East } \\
3.8\end{array}$} & \multirow{2}{*}{$\begin{array}{r}\text { North } \\
-2.1\end{array}$} & \multirow{2}{*}{$\begin{array}{c}\text { Vertical } \\
-1.2\end{array}$} & \multirow{2}{*}{$\begin{array}{c}\text { East } \\
0.8\end{array}$} & \multirow{2}{*}{$\begin{array}{c}\text { North } \\
0.1\end{array}$} & \multirow{2}{*}{$\begin{array}{c}\text { Vertical } \\
0.0\end{array}$} \\
\hline & 140.60 & 42.80 & & & & & & \\
\hline 0133 & 142.30 & 42.73 & 26.6 & -15.9 & -4.7 & 1.1 & -1.8 & -0.4 \\
\hline 0134 & 143.10 & 42.70 & 48.0 & -43.9 & -20.9 & 0.7 & -1.7 & -0.3 \\
\hline 0135 & 141.07 & 42.67 & 6.1 & -2.3 & -1.6 & 1.0 & -1.1 & 0.2 \\
\hline 0138 & 143.46 & 42.55 & 56.6 & -44.9 & -16.2 & 0.7 & -1.3 & -0.5 \\
\hline 0141 & 142.06 & 42.48 & 17.9 & -7.1 & -3.1 & 1.8 & -1.8 & -0.9 \\
\hline 0142 & 142.57 & 42.25 & 36.0 & -8.0 & -10.7 & 3.1 & -3.4 & -2.5 \\
\hline 0144 & 142.94 & 42.13 & 52.4 & -10.2 & -18.5 & 6.0 & -4.7 & -1.1 \\
\hline 0148 & 141.14 & 41.83 & 2.8 & -0.0 & 0.3 & 0.8 & -0.1 & -1.1 \\
\hline 0149 & 140.32 & 41.60 & 1.2 & -0.5 & 1.1 & 0.1 & -0.1 & -0.8 \\
\hline 0150 & 140.88 & 41.46 & 0.8 & -0.1 & -1.6 & 0.4 & -0.1 & -0.4 \\
\hline 0152 & 141.37 & 40.97 & 0.7 & 0.0 & -1.2 & 0.3 & -0.4 & 0.4 \\
\hline 0153 & 141.20 & 40.63 & -0.1 & -0.9 & -1.2 & 0.7 & -0.2 & -0.7 \\
\hline 0156 & 141.51 & 40.52 & -1.4 & -0.3 & -0.3 & 1.2 & -1.0 & -0.2 \\
\hline 0513 & 144.08 & 43.44 & 4.2 & -7.8 & -2.0 & 0.1 & -0.4 & 0.2 \\
\hline 0516 & 141.89 & 43.25 & 11.0 & -8.3 & -0.9 & 0.2 & -1.4 & 0.5 \\
\hline 0532 & 143.32 & 42.13 & 75.4 & -34.5 & -19.4 & 4.5 & -2.8 & -0.4 \\
\hline 0533 & 141.45 & 41.40 & 1.0 & -0.2 & 0.9 & 1.4 & -0.6 & -0.6 \\
\hline 0786 & 142.95 & 43.33 & 13.9 & -21.7 & -3.1 & 0.6 & -1.3 & -1.3 \\
\hline 0789 & 142.87 & 43.01 & 26.7 & -29.6 & -9.7 & -0.2 & -1.5 & 1.9 \\
\hline 0791 & 143.50 & 42.81 & 34.1 & -40.2 & -14.3 & 0.5 & -1.0 & -0.5 \\
\hline 0793 & 143.15 & 42.49 & 65.1 & -43.0 & -28.5 & 0.0 & -3.3 & 0.5 \\
\hline
\end{tabular}

the postseismic displacements. By using one sensor, GPS, displacements for both seismic and aseismic displacements can be quantitatively assessed, providing critical information for studies of fault properties.

The tuned Kalman filter provides an effective means of both estimating static offsets and suppressing time-varying GPS errors. No a priori information is used other than the times of the two earthquakes, which are used to define the white noise position updates. Drawbacks of the method are that the correlated nature of noise in subdaily GPS time series is ignored and no geophysical model is assumed for motion. An alternative method of studying postseismic deformation with GPS data uses the Network Inversion Filter of Segall and Matthews (1997). This methodology uses a geophysical model that contrains motion according to userdefined faults, while allowing for common-mode errors that are known to exist in GPS time series. Although more typically used with daily position estimates (e.g. Miyazaki et al., 2004a), Miyazaki and Larson (2008) utilized the Network Inversion Filter with the white noise position estimates for this event, simultaneously removing commonmode errors. They used the static offsets from Tables 2-3 to remove the effects of the mainshock and aftershock. They found that afterslip propagation is non-uniform, changing in the time period between the earthquakes and after the large aftershock. This is consistent with the changes in deformation rate seen in the individual time series produced for this study. The Tokachi-oki slip history is also consistent with non-uniform frictional properties on the plate interface.

\section{Discussion and Conclusions}

A methodology has been developed and tested for measuring coseismic and postseismic deformation using continuously operating GPS sites. Rather than rely on a tra- ditional GPS analysis that uses 24-hour averages of GPS observations to calculate position, this method uses a tuned Kalman filter to allow both rapid position changes associated with earthquakes and rapid postseismic deformation. While this study used the Kalman filter from the GIPSY software, other GPS softwares could also be used. For these softwares the position estimates should be estimated independently, followed by a Kalman filter that can be run offline.

The Tokachi-oki earthquake provides an ideal GPS dataset for this study. The GPS network in operated during this great earthquake without significant data outages. The continued expansion of the GPS constellation and the orbit accuracy provided by the International GNSS Service makes it possible to estimate high-rate positions with much greater precision than would have been possible when GEONET was first installed over 10 years ago.

Acknowledgments. This study was supported by a JSPS fellowship that funded the author's visit to Japan where she was hosted by T. Kato at the University of Tokyo. Grants USGS 05HQGR0015, NASA NAG5-13745, NSF EAR 0609646 and NSF EAR0538116 also contributed to this research. The GPS network in Japan is operated by the Geographic Survey Institute. The GIPSY software was provided by Caltech-JPL. Kyuhong Choi and Andria Bilich are acknowledged for their input on analysis strategies.

\section{References}

Altamimi, Z., P. Sillard, and C. Boucher, ITRF2000: A new release of the International Terrestrial Reference Frame for earth science applications, J. Geophys. Res., 107(B10), 2214, doi:10.1029/2001JB000561, 2002.

Blewitt, G., Carrier phase ambiguity resolution for the Global Positioning System applied to geodetic baselines up to $2000 \mathrm{~km}$, J. Geophys. Res., 94(B8), 10187-10203, doi:10.1029/89JB00484, 1989.

Choi, K., Improvements in GPS Precision: $10-\mathrm{Hz}$ to One Day, Doctoral Dissertation, University of Colorado, 2007. 
Geographical Survey Institute of Japan, Report for the 154-th Coord. Comm. Earthquake Prediction, 2003.

Hatanaka, Y., M. Sawada, A. Horita, and M. Kusaka, Calibration of antenna-radome and monument-multipath effect of GEONET-Part 1: Measurement of phase characteristics, Earth Planets Space, 53, 13-21, 2001.

Johnson, K., R. Burgmann, and K. Larson, Frictional afterslip following the 2004 Parkfield, California earthquake, BSSA, 96(4b), S321, DOI: 10.1785/gssrl.77.4.491, 2006.

Koketsu, K., K. Hikima, S. Miyazaki, and S. Ide, Joint inversion of strong motion and geodetic data for the source process of the 2003 Tokachioki, Hokkaido, earthquake, Earth Planets Space, 56, 329-334, 2004.

Langbein, J. et al., Preliminary report on the 28 September 2004, M6.0 Parkfield, California, earthquake, Seismol. Res. Lett., 76, 1-17, 2005.

Larson, K., P. Cervelli, M. Lisowski, A. Miklius, P. Segall, and S. Owen, Volcano Monitoring using GPS I. Filtering Strategies, J. Geophys. Res., 106, 19,453-19,464, doi:10.1029/2001JB000305, 2001.

Larson, K., P. Bodin, and J. Gomberg, Using $1 \mathrm{~Hz}$ GPS Data to Measure Deformations Caused by the Denali Fault Earthquake, Science, 300, 1421-1424, doi: 10.1126/science.1084531, 2003.

Larson, K., A. Bilich, and P. Axelrad, Improving the precision of highrate GPS, J. Geophys. Res., 112, B05422, doi:10.1029/2006JB004367, 2007.

Lichten, S. and J. Borders, Strategies for High-precision Global Positioning System Orbit Determination, J. Geophys. Res., 92, 12,751-12,762, 1987.

Miura, S., Y. Suwa, A. Hasegawa, and T. Nishimura, The 2003 M8.0 Tokachi-Oki earthquake: How much has the great event paid back slip debts?, Geophys. Res. Lett., 31, L05613, doi:10.1029/2003GL019021, 2004.

Miyazaki, S. and K. Larson, Coseismic and early postseismic slip for the 2003 Tokachi-oki earthquake sequence inferred from GPS data, Geophys. Res. Lett., 35, L04302, doi:10.1029/2007GL032309, 2008.
Miyazaki, S., T. Saito, M. Sasaki, Y. Hatanaka, and Y. Iimura, Expansion of GSI's nationwide GPS array, Bull. Geogr. Surv. Inst., 43, 23-24, 1997.

Miyazaki, S., T. Iwabuchi, K. Heki, and I. Naito, An impact of estimating tropospheric delay gradients on precise positioning in the summer using the Japanese nationwide GPS array, J. Geophys. Res., 108(B7), 2335, doi:10.1029/2000JB000113, 2003.

Miyazaki, S., P. Segall, J. Fukuda, and T. Kato, Space time distribution of afterslip following the 2003 Tokachi-oki earthquake: Implications for variations in fault zone frictional properties, Geophys. Res. Lett., 31, L06623, doi:10.1029/2003GL019410, 2004a.

Miyazaki, S., K. Larson, K. Choi, K. Hikima, K. Koketsu, P. Bodin, J. Haase, G. Emore, and A. Yamagiwa, Modeling the rupture process of the 2003 Tokachi-Oki earthquake using 1-Hz GPS data, Geophys. Res. Lett., 31(21), L21603, doi:10.1029/2004GL021457, 2004b.

Niell, A. E., Global mapping functions for the atmosphere delay at radio wavelengths, J. Geophys. Res., 101(B2), 3227-3246, doi:10. 1029/95JB03048, 1996.

Ozawa, S., M. Kaidzu, M. Murakami, T. Imakiire, and Y. Hatanaka, Coseismic and postseismic crustal deformation after the $M_{w} 8$ Tokachi-oki earthquake in Japan, Earth Planets Space, 56, 675-680, 2004.

Segall, P. and M. Matthews, Time dependent inversion of geodetic data, $J$. Geophys. Res., 102, 391-409, 1997.

Wald, D. and R. Graves, Resolution analysis of finite fault source inversion using one- and three-dimensional Green's functions 2.: combining seismic and geodetic data, J. Geophys. Res., 106(B5), 8767-8788, 2001.

Yamanaka, Y. and M. Kikuchi, Source processes of the recurrent Tokachioki earthquake on September 26, 2003, inferred from teleseismic body waves, Earth Planets Space, 55, e21-e24, 2003.

K. M. Larson (e-mail: kristinem.larson@gmail.com) and S. Miyazaki 